


\section{Utopía humanista de Alfonso Reyes en Monterrey}

Jaime Villarreal

Universidad de Guanajuato

Resumen:

Este texto discute y enmarca el proyecto humanista pensado por Alfonso Reyes para Monterrey, explora algunos ensayos donde el escritor acuña arquetipos sobre la historia, vocación y carácter de la región y de sus habitantes. La discusión se centra en su "Voto por la Universidad del Norte" (1933) en el que plantea la necesidad de renovar la tradición humanista. Esta investigación sirve también para reconstruir parte del diálogo y polémicas que han caracterizado el campo cultural regiomontano en el siglo XX.

Palabras clave: Alfonso Reyes, humanismo mexicano, región intelectual, campo cultural regiomontano, siglo XX.

\section{Abstract:}

This text discusses and frames the humanist project designed by Alfonso Reyes for Monterrey, it explores several essays where the writer coined archetypes on the history, vocation and character of the region and its inhabitants. The discussion focuses on his "Voto por la Universidad del Norte" (1933), which proposes the need to renew the humanist tradition. This research also serves to reconstruct part of the 
dialogue and controversy that has characterized Monterrey's cultural field in the twentieth century.

Keywords: Alfonso Reyes, Mexican Humanism, Intellectual Region, Monterrey's cultural field, Twentieth century.

$\mathrm{H}$ ablar de cultura y humanismo en nuestros días parece casi demodé. Tal vez fue una tendencia intelectual de primer orden en tiempos del Alfonso Reyes (1889-1959) ateneísta, pero no lo es más. Dicha directriz fue tan vital en la primera mitad del siglo XX latinoamericano que aquellos humanistas dictaron las líneas de la política cultural y educativa de nuestros países, las cuales se concretaron en instituciones que perduran hasta nuestros días. Desde el siglo XIX, esta vertiente cultural ocupó un lugar privilegiado como base de la educación de los poderosos y ese papel primordial se vio reflejado en la formación humanista de algunos jefes de estado decimonónicos, quienes como el resto de los letrados con frecuencia tuvieron que dejar la pluma y tomar las armas. Ya en el siglo XX destacan los casos del ateneísta José Vasconcelos, que llegó a ser candidato a la presidencia de México (1929), y del novelista Rómulo Gallegos, electo presidente de Venezuela en 1947, aunque un golpe militar lo destituyó en 1948.

Esa situación general motivó una réplica regional. Gracias al creciente prestigio del humanismo de principios de siglo, que tuvo su mayor referente nacional en el grupo ateneísta, se produjeron en Monterrey instituciones que perduran hasta la actualidad, como las universidades públicas y privadas o las escuelas normalistas. En esta particular historia local sobresale hasta hoy el extraordinario periodo al frente del gobierno estatal de un consumado humanista, Raúl Rangel Frías (1955-1961), todo lo cual, sin embargo, ha desembocado en una progresiva pérdida de relevancia social de la cultura y del humanismo hasta llegar a los albores de la actualidad 
caracterizada por la democracia incipiente, los medios masivos hegemónicos y la economía de mercado.

El proceso que ha experimentado el discurso humanista regional es muy similar, con sus debidas distancias, del vivido en Latinoamérica: en el paso entre el siglo XIX y XX, la cultura clásica y el humanismo en general fueron considerados elementos fundamentales de la formación de los poderosos. ${ }^{1}$ Es muy interesante y destacable la capacidad de algunos escritores e intelectuales para capitalizar esa relevancia, el músculo político que tuvo la intelectualidad, para concretar instituciones que aún perduran. El ejemplo sentimentalmente más cercano a Monterrey es precisamente el de Reyes, quien se repuso del destierro europeo posterior a la muerte de su padre porfirista, Bernardo Reyes, para hacer una prominente carrera en la diplomacia mexicana y, a la postre, volver a México para fundar bastiones culturales como la Casa de España (1938) — antecedente de El Colegio de México (1940)—, El Colegio Nacional (1943) o el Centro Mexicano de Escritores (1951).

Pero Reyes, si bien es el gran referente intelectual de dicha cultura local, jugó presencialmente en otra liga, la de la creación de la patria, la nacional mexicana y la internacional latinoamericana. La pertenencia de Reyes a la cultura local regiomontana ha sido tema de debate, en particular desde la muerte del escritor hasta nuestros días. Esta polémica se volvió más significativa cuando se proyectó trasladar su biblioteca, formada y establecida por él en la

${ }^{1}$ El ensayista brasileño Idelber Avelar explica cómo los estados latinoamericanos descartaron la asistencia de los intelectuales públicos y, con ellos, al humanismo: "Mientras que la literatura históricamente había florecido a la sombra de un precario aparato estatal, ahora un estado cada vez más tecnocrático dispensaba sus servicios; si siempre había sido un instrumento clave en la formación de una élite letrada y humanista, ahora esa élite la dejaba de lado por teorías económicas más eficaces, importadas de Chicago; las facultades de literatura y filosofía habían sido medios vitales de reproducción ideológica, pero ahora la ideología llevaba la máscara neutral de la tecnología moderna" (46). 
capital del país, al inmueble que hoy ocupa en la Universidad Autónoma de Nuevo León. En 1972 la nación adquirió la biblioteca por decreto presidencial de Luis Echeverría y en 1980 el presidente José López Portillo determinó su traslado a Nuevo León. Muchas voces de escritores, académicos e intelectuales capitalinos, entre los que destacaron Octavio Paz y Juan García Ponce ${ }^{2}$, se opusieron en alguna medida a ese proyecto. Al final, protagonizaron las gestiones para establecer recinto y acervo en Monterrey (1980) tanto la viuda de Reyes, Manuela Mota, la nieta del ensayista, Alicia Reyes, así como el rector de la Universidad, Luis E. Todd, y el político y escritor regiomontano Raúl Rangel Frías. El punto de vista regiomontano de esa pugna, polémica que en su momento distanció los dos ámbitos culturales, quedó ilustrada en el artículo de Rangel Frías titulado "Entre Alfonso Reyes y Monterrey":

Ofusca el entendimiento de algunos intelectuales, poetas y críticos de la ciudad de México, que han alzado su voz contra la resolución presidencial de trasladar a Monterrey la Biblioteca de Don Alfonso Reyes, un valioso sentimiento de pena, aunque mezclado de prejuicios e incomprensiones (1980: 37).

De cualquier manera, el apoyo moral, no presencial, del ensayista quedó manifiesto en cartas y publicaciones, entre las cuales destaca su señero "Voto por la Universidad del Norte", escrito desde Brasil poco antes de la fundación de la Universidad de Nuevo León en 1933, la cual adquirió autonomía en 1971; más adelante comentaré ese ensayo del regiomontano. Dicha institución, sin duda fue el acontecimiento que potenció y profesionalizó la producción cultural en la entidad.

2 "Octavio Paz, Juan García Ponce e IF se oponen al traslado de la Capilla Alfonsina” (Unomásuno, 18 de junio de 1978). 


\section{El desfase entre lo local y lo nacional}

¿De qué está hecha esa otra liga local, esa batalla ideológica que produjo la llamada cultura del trabajo? Sin duda el medio regiomontano refleja el empoderamiento de las élites construidas alrededor de los procesos de industrialización, el primero de ellos nacido y desarrollado a partir del largo periodo de gobierno de Bernardo Reyes (1889-1909), a la postre el ciclo de paz y desarrollo que permitió la prosperidad con su inversión en infraestructura y exenciones fiscales. Ese tiempo de paz y control. La marca del reyismo, por ejemplo, en el campo de las publicaciones se reflejó en la casi desaparición del periodismo político de oposición ${ }^{3}$, lo que propició una prensa dedicada a la llana labor informativa y a la difusión literaria ${ }^{4}$ como mero aderezo. Si bien la relación entre Bernardo Reyes y Díaz no fue totalmente tersa, significó toda una etapa de estabilidad y de configuración estructural de los grupos de poder: empresarios, iglesia y gobierno.

Poco antes del advenimiento de los conflictos revolucionarios, que sin duda se vivieron con muchos menos sobresaltos en el noreste del país que en el centro, se presentó la posibilidad para que el mismo Bernardo Reyes capitalizara su liderazgo político llegando a la presidencia, pero fue incapaz de oponerse a Díaz, huyó del país y abandonó a sus partidarios ya establecidos el año anterior a la elección de 1910. El espacio vacío dejado por Reyes fue ocupado por

${ }^{3}$ A diferencia de lo ocurrido en el centro del país, cuya prensa desde principios del siglo XIX se caracterizó por su combatividad, a partir de la fundación del Diario de México en 1805. Ahí, a fines de ese siglo, los intelectuales, algunos incluso aliados de Díaz en su etapa liberal, establecieron un frente crítico a través de la opinión pública desde que se perfiló la dictadura. Prueba de ello son publicaciones como la satírica El Hijo del Ahuizote fundada en 1885 o el periódico Regeneración fundado por los hermanos Flores Magón en 1900.

${ }^{4}$ Así lo observa Isidro Vizcaya en Los orígenes de la industrialización de Monterrey (2006). 
Madero, quien se proclamó en contra de todo lo que representó el gobierno porfirista, alcanzó la presidencia (1911), y con ello dio inicio al periodo revolucionario, que adquirió su plenitud luego de su asesinato (1913) al lado del vicepresidente Pino Suárez.

Este muy conocido error histórico de Bernardo Reyes, que pudo y no quiso y luego quiso y no pudo, representa también la posibilidad fallida de llevar el modelo norteño de progreso al centro de la nación en temporada de cambio y reconstrucción. Tiempo después, la plena desazón revolucionaria generó, además de diversos enfrentamientos armados, gran inestabilidad en la conducción del estado, tanto así que entre 1910 y 1917 Nuevo León fue administrado por 12 gobernadores; los grupos en pugna que iban imponiéndose en la región también nombraban a su respectivo jefe del gobierno.

Así, un concreto desfase de lo local con lo nacional es sin duda una de las marcas que define la relación de las clases poderosas locales con el modelo de la Revolución institucionalizada que surgirá de la maraña de conflictos revolucionarios. También esta divergencia será uno de los orígenes del particular campo cultural generado y reproducido desde dicha circunscripción en las esferas legitimadas, "cultas", oficiales. Uno de los puntos álgidos de definición de la disonancia del centro con lo regional se dio en el gobierno socialista-nacionalista de Lázaro Cárdenas (1934-1940), con su énfasis en la reforma agraria, la organización de obreros y campesinos (la CTM y la CNC fueron creadas en el sexenio cardenista), la nacionalización de recursos naturales, la protección de los republicanos espańoles exiliados y el fortalecimiento del PNR. Fue tal la confrontación que Cárdenas debió ceder ante la presión para dialogar directamente con los empresarios regiomontanos agremiados. La discordancia entre Monterrey y el centro fue, en el tiempo de los primeros gobiernos revolucionarios, un choque de modelos socioeconómicos y de regulaciones; en el caso del go- 
bierno Cardenista, fue un conflicto entre el socialismo nacionalista central frente a la economía de mercado local-regional, apuntalada con capitales estadounidenses.

Como lo destaca Eduardo Ramírez (2009), el intento del exgobernador del estado Aarón Sáenz (Monterrey, 1891-Ciudad de México, 1983) para llegar a la presidencia, frustrado por el propio Plutarco Elías Calles, bajo cuyo mandato (1924-1928) fungió como secretario de Relaciones Exteriores, es uno de los primeros golpes directos del centralismo revolucionario al empresariado de Nuevo León. Lo mismo ocurrió con las iniciativas centrales para homologar la Ley Federal del Trabajo, el llamado proyecto Portes Gil, que emuló la legislación de la Italia fascista, y organizar la actividad de obreros y campesinos. Como respuesta discrepante a dichas propuestas y a iniciativa del director de Cervecería Cuauhtémoc, Luis G. Sada, los industriales de Monterrey y de otras regiones del país crearon la Confederación Patronal de la República Mexicana (Coparmex); entre las razones para establecer dicha asociación argumentaron: “a) la existencia de problemas sociales creados inevitablemente por la relación entre quienes representan el capital y quienes integran el sector de los trabajadores; b) la influencia preponderante que de tiempo atrás tomaban las ideas socialistas radicales" (Alba Vega ápud Ramírez, 2009: 21).

\section{El campo regiomontano}

La particular disonancia social, política y económica ha enmarcado y definido en Monterrey y en el estado un particular campo cultural en las esferas predominantes y oficiales, aislado no sólo por la distancia y accidentes geográficos del centro del país, cuya preeminencia en la cultura nacional es avasallante. Uno de los rasgos evidentes de la generación cultural en Monterrey es su marcado regionalismo. Lo que el joven crítico Ignacio Sánchez Prado 
llama nación intelectual, "un conjunto de producciones discursivas, enunciadas sobre todo desde la literatura, que imaginan, dentro del marco de la cultura nacional hegemónica, proyectos alternativos de nación" (2009: 1), se presenta a escala en el campo cultural regiomontano más bien como región intelectual, como proyectos alternativos de región.

La tendencia a ocuparse de lo regional reforzó sin duda la brecha entre lo local y lo nacional y, en muchos sentidos, también dejó fuera de la lucha por la definición de la cultura nacional ejemplar a muchos intelectuales que ciñeron su ámbito de acción a esta zona del país. Como muestra de la producción de discursos que han dado sentido al campo cultural regional, y como parte de un proyecto mayor sobre este tipo de disertaciones, comentaré aquí un par de textos señeros de Reyes enunciados desde distintos contextos sociales e históricos: "Voto por la Universidad del Norte" (6 de enero de 1933) y "Regiomontanos"5 (Universidad, 2 de septiembre de 1943), leído en representación del estado de Nuevo León en la II Feria del Libro de la Ciudad de México en 1943.

\section{La contribución de Reyes}

El año pasado, con motivo del 80 aniversario de la fundación de la Universidad Autónoma de Nuevo León, el ensayo de Reyes ha sido uno de los más retomados oficialmente como emblemático y forjador de la principal casa de estudios del estado. Difiero en esta consideración, ya que el exhorto del ensayista, que cumplía labores diplomáticas en Brasil en aquel entonces, con toda la relevancia que pudo haber tenido, llegó en un momento en que las gestiones relacionadas con la creación de la Universidad ya habían sido realizadas: "La realidad me ha sorprendido, llegando a pa-

${ }^{5}$ Utilizo la versión de las Obras completas (1958a: 176-182). 
sos agigantados, y me encuentra casi desprovisto" (1958b: 450), aclara el escritor al inicio de su argumentación. Fue más bien una expresión de apoyo moral. Mucho más decisivos fueron los papeles jugados por los jóvenes escritores José Alvarado y Raúl Rangel Frías en la creación de la Universidad, de la misma manera en que la actuación de Reyes fue vital en la consecución de esas otras instituciones culturales fundadas por él en la capital del país. Uno de los sustentos importantes para la creación de la Universidad de Nuevo León lo otorgó el político Aarón Sáenz Garza, “al incluir en su último informe de gobierno [1931] una extensa argumentación a favor de dicho proyecto; aunque — muy consciente de los límites estatales - habló de la factibilidad de fundar la Universidad de Nuevo León, no la del Norte" (Morado Macías, 2007: 91).

Por otra parte, la juiciosa construcción de lo regional en aquel ensayo solidario quedó más evidente en la reiteración que hizo Reyes de algunos de sus pasajes en un par de discursos publicados posteriormente en Monterrey: uno pronunciado durante los Juegos Florales de 1939 (El Porvenir, 17 de septiembre de 1939) y el ya mencionado "Regiomontanos". Sólo apunto un pasaje breve de "Regiomontanos", sin duda constituyente de esa imagen idealizada de los pioneros de la localidad y de las carencias que hubieron de enfrentar:

En otras zonas la naturaleza fue más dadivosa. Allá hubo que arrancárselo todo, y esta pugna feliz, esta creación sobre la nada es una de las demostraciones más patentes de la cultura y de las posibilidades del espíritu. Porque el espíritu es, sobre todo, rectificación y superación, modelación que transfigura el dato bruto de las realidades exteriores (1958a: 178).

Es significativo el empleo del concepto hegeliano de espíritu en la disertación de Reyes, término que designa la manera en que lo subjetivo se cristaliza en la moralidad, el estado y la historia, lo que 
Hegel llamó desde su perspectiva occidentalista espiritu objetivo. Fue en su disertación original ("Voto por la Universidad del Norte") donde el ensayista acuñó ciertos formulismos que sin duda hicieron mella en la autodefinición del arquetipo regiomontano construido desde la intelectualidad: "Sin asomo de ironía pudiera afirmarse que el regiomontano es un héroe en mangas de camisa, que es un paladin en blusa de obrero, que es un filósofo sin saberlo, un gran mexicano sin actitudes estudiadas para el monumento y hasta creo que un hombre feliz" (1958b: 452-453; el énfasis es mío). Lo mismo ocurre con sus epítetos dedicados a Monterrey: "Honesta fábrica de virtudes públicas, vivero de ciudadanos, la he llamado a veces" (1958b: 452). Por otro lado, Reyes escribió también de forma modélica sobre la vocación, a la vez defensiva y coordinante, de Monterrey en el contexto de las relaciones entre México y Estados Unidos, que en el XIX había obligado al estado mexicano a ceder más de la mitad de su territorio y en el XX invadió suelo mexicano en otro par de ocasiones.

Que no será la ciega agresividad, que no será el vano sentimentalismo, ni tampoco los precipitados casuales de un régimen escolar hecho a pedazos, quienes nos protejan, sino sólo el conocimiento y la voluntad educada y rectificada, sólo un sistema de principios y acciones bien escogidos y armonizados. Un ser se define, y también se pierde, por sus contornos; y esta epidermis de la frontera debe ser cuidadosamente sensibilizada e irrigada por la cultura, para que ejerza con normalidad, eficacia y simpatía sus complejas funciones respiratorias y de relación con el no yo. De ello aprovecharemos a un tiempo los dos vecinos del río internacional, del río que nos separa y nos junta; y lo que sirva para mejor sustentarnos en nuestro propio temperamento y en nuestras más apuradas tradiciones, habrá de servir asimismo para mejor amistarnos con la gran nación que, desde la otra ribera, nos contempla y aguarda (1958b: 450-451). 
En los apartados III y IV de ese ensayo, Reyes sitúa la construcción intelectual e histórica de la región, cifrada en el desarrollo de la ciudad de Monterrey. Sin mencionarlo por nombre, se refiere a las virtudes de la administración de su padre en el gobierno del estado por más de 20 años, "cuyos méritos sólo unos cuantos obcecados se atreven ya a escatimar" (1958b: 452), como el periodo de crecimiento y concreción de la unidad urbana. Con expresión sutil, Reyes sitúa en esta misma etapa de crecimiento en Monterrey los primeros y pacíficos avances del país en la organización laboral y política (a diferencia, claro, del progreso conseguido tiempo después mediante el conflicto revolucionario): "tierra donde el derecho obrero mexicano dio sus primeros pasos, sin alarmar ni escandalizar a nadie porque era un crecimiento natural de aquel suelo" (1958b: 458).

El más asertivo proyecto de región de Reyes, como ya se ha dicho, construido desde el extranjero, con un tono idealizante y enmarcado en su más general edificación de las naciones mexicana y latinoamericana, se concreta en su definición programática de la Universidad del Norte y de esas otras universidades regionales que servirían para irrigar a lo largo del territorio del país la centralizada cultura nacional producto de la Revolución (centralismo equivalente al del caso, mencionado en su argumentación, de la Francia posrevolucionaria del siglo XIX): "La cultura metódicamente esparcida bañaría entonces el conjunto de nuestra población juvenil" (1958b: 456). Esa aspiración humanista del escritor ubica en el centro de la organización social a la Universidad, al conocimiento y cultura de ella emanados:

Entiendo más bien que la creación de nuestra Universidad significa un cambio de acento en la atención pública: - la cultura, que antes crecía como al lado, pasará a constituir el núcleo, el meollo. La organización escolar dará el armazón, y en ella se trabarán como derivaciones indispensables todas las demás actividades téc- 
nicas, la circulación del comercio y aun los entreactos de la vida mundana. De suerte que el último martillo que bata el hierro en el último taller resulte concadenado a la fórmula algebraica que los estudiantes inscriben en el encerado de las aulas. De suerte que, si ha de presentarse entre nosotros otro tipo de humanista como José Eleuterio González — de noble recordación—, no se lo vea como un cuerpo extraño, sino como una parte armónica y necesaria de nuestro existir, al igual del ingeniero que rige los telares y gobierna las máquinas de artefactos (1958b: 453).

Este programa utópico de Reyes contiene ya en germen una polémica ideológica que se desarrollará con el tiempo entre la cultura universitaria, de la educación pública y humanista, y la de las élites locales políticas y empresariales. Uno de los resultados concretos y casi inmediatos de esa polémica fue sin duda la fundación, a iniciativa de un grupo de empresarios prominentes de la ciudad, encabezados por Eugenio Garza Sada, del Tecnológico de Monterrey en 1943 (año de la segunda fundación de la Universidad). Lo mismo significaron las presiones que sufrieron al frente de la Universidad rectores como Raúl Rangel Frías (1949-1955), quien hubo de disputar los terrenos federales con los que avanzaría después, ya durante su periodo como gobernador del estado (1955-1961), la construcción de la Ciudad Universitaria; así como sucedió con el escritor José Alvarado, quien fue nombrado rector en 1961 por el gobernador Eduardo Livas, pero que por motivos de salud tomó posesión hasta 1962 y dejó el puesto en febrero de 1963, obligado por el ataque sistemático ejercido por un periódico local en contra de él y de su familia.

Es necesario destacar, por aquello de confundir el espíritu conciliador con apolitismo, el énfasis en la educación política, y la preparación para la convivencia del hombre con el hombre, que a Reyes le pareció tan necesaria en nuestro país. Esta tendencia pue- 
de leerse además como una vía de transformación del humanismo como tradición de la cual él mismo provenía:

No nos bastaría ya con el antiguo humanismo, hecho de cultura literaria; no nos bastaría con el que nació del positivismo, hecho de cultura científica. Necesitamos completar el cuadro de urgencias actuales, dando sitio en la nueva universidad a una forma de cultura política (Lo cual, de paso, devolviendo su seriedad al problema, desterraría, en buenhora, la "politiquería" interior en que se distraen y aun se sacrifican a veces los escolares (1958b: 458).

Un discurso alentador y de espíritu conciliador, marca de Reyes, a pesar de sus matices. A la vez impulsa ese proyecto revolucionario educativo que significó la fundación de la Universidad de Nuevo León y produce una concepción regional proyectada y construida desde la perspectiva intelectual. Un texto al que volverán los ensayistas regiomontanos, incluso en la actualidad, para tomar ejemplo y guía. También debo señalar que se trata de una visión tan mediadora como idealizada, que incluye sin duda en su propio tejido una contradicción polémica: el choque de la tradición porfirianapositivista, reconocida por Alfonso Reyes (en el gobierno de su padre) como el origen de la sociabilidad local, con el impulso renovador cultural y educativo revolucionario proveniente del centro y adoptado por jóvenes humanistas como Alvarado y Rangel Frías.

Gracias a las múltiples condiciones históricas cumplidas a finales del siglo XIX, entre las que se encuentran el amasamiento de los capitales locales, la estabilidad social porfirista, las relaciones económicas coyunturales con los Estados Unidos y la llegada de la red ferroviaria, Monterrey fue la región mexicana en la que con mayor fluidez se ha transitado hacia la industrialización y la economía de mercado. 
A diferencia de lo que acaecía en otras áreas de América Latina en estos años, Monterrey se lanzó al capitalismo sustentándose en la producción fabril, lo que le permitió convertirse en el núcleo hegemónico de una vasta región del norte de México y ser cuna de una burguesía que desde entonces ha mostrado un peso específico innegable en la economía del país (Cerutti, 2006: 112).

Y si bien Reyes apunta la necesidad de un cambio en el papel de los humanistas cada vez más especializados de su tiempo hacia la educación política que les otorgue mayor acceso y capacidad de acción en la organización de la vida social, en su proyecto, la tradicional posición de los letrados decimonónicos al lado de los pode$\operatorname{rosos}^{6}$ quedaría institucionalizada en esa función central que para él tendría la Universidad. En ese sentido, su discurso de resistencia, en cuanto apoya el empoderamiento en la región de una cultura política universitaria, también apuntala y normaliza ("era un crecimiento natural de aquel suelo") la institución capitalista que socializa la ética del trabajo, ${ }^{7}$ difundida en Monterrey como la cultura del trabajo. Esta carencia crítica ha caracterizado, desde mi punto de vista, buena parte de las producciones culturales e intelectuales

${ }^{6}$ En el amplísimo sentido decimonónico de lo literario en Latinoamérica (presente ya incluso en la obra de Fernández de Lizardi), un escritor como Francisco Zarco puntualizaba en su célebre "Discurso sobre el objeto de la literatura" (1851) la utilidad y sentido de dicha práctica cultural: "Y el filósofo, el naturalista, el economista, son literatos. Se ha extendido pues este círculo que se creía reducido por algunos al número insignificante de tristes versificadores, sin inspiración ni entusiasmo, y vemos que la literatura abraza todos los conocimientos útiles y sirve de poderoso auxiliar al que se entrega a investigaciones científicas y al que es llamado a dirigir los destinos de las naciones" (170).

${ }^{7}$ Max Weber, en La ética protestante y el espiritu del capitalismo (1905), describe esa cultura típica del calvinismo (fundante del progreso norteamericano) que procura racionalmente el éxito económico. Habría que rastrear el origen y desarrollo ideológico de la ética del trabajo en Monterrey a partir de la influencia cultural norteamericana en la región. 
regiomontanas. En el caso del ensayista, su discurso sirve más para criticar ciertos aspectos de la política centralista revolucionaria que para poner en la balanza el campo cultural regiomontano poco especializado, apenas en ciernes, en la primera mitad del siglo XX.

Por otro lado, en el marco hispanoamericano y a diferencia del estilo inaugurado, en varios sentidos, por Jorge Luis Borges (1899-1986), quien acercó o fundió el ensayo y los registros ensayístico-especulativos con la ficción y es hasta la fecha referencia para escritores de diversos orígenes, Reyes "hizo del género la gran herramienta para expandir entre muchos la cultura de pocos y resolver así uno de los grandes desafíos de la Revolución mexicana: cómo multiplicar el conocimiento y hacerlo llegar a capas cada vez más amplias de la población” (Weinberg, 2007: 84). Así, Raúl Rangel Frías y José Alvarado, quienes desde estudiantes militaron en el movimiento vasconcelista impulsor del nacimiento de la Universidad de Nuevo León, como escritores abrazaron la directriz ética intelectual cobijada por Reyes y por el dominicano Pedro Henríquez Ureña (1884-1946).

La renovación y replanteamiento de esa cultura crítica sin duda se presenta como una necesidad en un contexto en que la marca Monterrey y sus valores pierden consistencia ante la cesión de empresas señeras de origen regional a manos de transnacionales y que, gracias a los conflictos sociales derivados de la calderonista guerra contra el narco, nos ha echado en cara la insuficiencia de directrices colectivas para responder a crisis venideras. Con este fin habría que releer el diálogo o el conflicto, local, nacional y transnacional, que ha producido culturalmente la actualidad. La reinterpretación de un proyecto intelectual integral y conciliador como el de Reyes puede guiar esa empresa. 


\section{Bibliografía}

Altamirano, Ignacio Manuel, 2002, La literatura nacional. Revistas, ensayos, bibliografías y prólogos, t. I, $2^{\text {a }}$ ed., México, Porrúa.

Avelar, Idelber, 2000, Alegorias de la derrota: la ficción posdictatorial $y$ el trabajo del duelo, Santiago, Cuarto Propio.

Cerutti, Mario, 2006, Burguesía y capitalismo en Monterrey 18501910, Tercera edición, Monterrey, Fondo Editorial de Nuevo León.

Franco, Jean, 1983, "En espera de una burguesía: la formación de la intelligentsia mexicana en la época de la independencia", en AIH, Actas VIII.

Genette, Gerard, 1989, Palimpsestos. La literatura en segundo grado, Madrid, Taurus.

Morado Macías, César, 2007, "Proyecto revolucionario y educación universitaria en Nuevo León", en Nuevo León en el siglo XX. La transición al mundo moderno. Del reyismo a la reconstrucción (1885-1939), t. I, César Morado Macías (coord,), Monterrey, Fondo Editorial Nuevo León, pp. 81-115.

Ramírez, Eduardo, 2009, El triunfo de la cultura. Uso politico y económico de la cultura en Monterrey, Monterrey, Fondo Editorial de Nuevo León/UANL, pp. 20-21.

Rangel Frías, Raúl, 1980, “Entre Alfonso Reyes y Monterrey”, en Alfonso Reyes: Instrumentos para su estudio, José Ángel Rendón Hernández (comp,), Monterrey, UANL / Biblioteca Central, pp. 37-43.

, 2009, "Teoría de Monterrey", en Renovada compañia. Antología de Armas y Letras (1944-1957), Víctor Barrera Enderle (comp,), Monterrey, UANL, pp. 35-43.

Rangel Guerra, Alfonso, 2002, "Universidad Autónoma de Nuevo León, Semblanza histórica", en La educación superior en el pro- 
ceso histórico de México. t. IV. Semblanzas de instituciones, David Piñera Ramírez (coord.), Mexicali, SEP / UABC /ANUIES, pp. 156-167.

Reyes, Alfonso, 1958a, "Los regiomontanos", en Obras completas. t. VIII, México, FCE, pp. 176-182.

, 1958b, "Voto por la Universidad del Norte", en Obras completas. t. VIII, México, FCE, pp. 450-459.

Sánchez Prado, Ignacio, 2009, Naciones intelectuales. Las fundaciones de la modernidad literaria mexicana (1917-1959), West Lafayette, Indiana, Purdue University Press.

Sarlo, Beatriz, 1994, Escenas de la vida posmoderna. Intelectuales, arte y videocultura en la Argentina, Buenos Aires, Ariel.

Vizcaya, Isidro, 2006, Los orígenes de la industrialización de Monterrey, Monterrey, Fondo Editorial de Nuevo León / ITESM.

Weinberg, Liliana, 2007, Pensar el ensayo, México, Siglo XXI editores. aceptado: 26 de febrero de 2015) 